\title{
Doing Math Modelling Outdoors- A Special Math Class Activity designed with MathCityMap
}

\section{Matthias Ludwig, Simone Jablonski}

Institute für Mathematics and Computer Science, Goethe- University Frankfurt, Germany.

\begin{abstract}
The use of smartphones in classrooms is unfortunately due to the restriction legislated by administrations not very popular. With the MathCityMap project (MCM) we show one possibility to use the own mobile device in a substancial and authentic learning environment. MathCityMap combine the well known math trail idea with the current technological possibilities of mobile devices. The MathCityMap is a two component system. The first component is a webportal (www.mathcitymap.eu) which served as a open access database for authentic math problems in the environment. The other component, the MCMApp, shows on a map where in the environment the problems are hidden. Additional it provides hints, feedback and a sample solution. To solve such an authentic MCM problem you need mathematical modelling competencies. We show with the help of one example in which way the students work with the tasks and how the system deal with different solution which occurs by solving a modelling task.
\end{abstract}

Keywords: Mobile phone; App; Mathematics; modelling; outdoor; real world. 


\section{Introduction}

Mathematical modelling, in the NCTM Standards known as connections, is not easy to teach. First there is a lack of good beginner modelling tasks even for undergraduates students and second a lot of so called modelling tasks are not authentic and not realistic (Vos 2011). With the MathCityMap-Project (MCM-Project, www.mathcitymap.eu) we like to motivate students to solve real world tasks by using expedient mathematical modelling ideas outside the classroom. The MCM-Project (see chapter 3) is based on the math trail idea introduced in Melbourne, Australia in 1984 (Blane \&Clarke, 1984). To solve a typical task which is provided by the MCM-app (e,g,. to calculate the mass of a rock) you need to transfer the real model into a mathematical model. The MCM-app provide hints, checks the answer of the user and gives a direct feedback.

\section{Theoretical Background}

\subsection{Math trail}

A math trail is a set of mathematical tasks or questions that are bound to objects from the real world. Usually they are located in walking distance. A math trail guide contains a map that displays interesting locations and descriptions of different tasks to discover mathematics in the environment. Shoaf, Pollak \& Schneider (2004) saw a potential in math trails to popularize mathematics since everyone (e.g. families) can walk them, the participants' work cooperatively and thus experiencing mathematics in a non-threatening environment. In addition, walking a math trail is a good way to make experiences with the perceptual motor system, which is the base of all mathematical concepts (Wittmann et al, 2012).

\subsection{Mobile technologies, motivation and hints}

The use of mobile technologies has significantly increased during the last few years. Internet usage via mobile phone, for example in Germany, has increased so much that $60 \%$ of all internet connentions in 2017 were provided by mobile phone (Statistisches Bundesamt, 2017). If one considers that $99 \%$ of the group of the 16- to 24-year-old Germans uses the internet, it is evident which important role the internet and especially mobile internet play in the students everyday life. Moreover, it shows that the percentage of students who use mobile technologies as mobile internet has greatly increased. Consequently, the appropriate technique for the MCM-project is available for many students now.

The use of mobile technologies to learn at any time and at any location is known as "mobile learning” (m-learning). Considering the definition of O’Malley et al. (O'Malley, Vavoula, Glew, Taylor, Sharples, \& Lefrere, 2003): “Any sort of learning that happens when the learner is not at a fixed, predetermined location, or learning that happens when the learner 
takes advantage of the learning opportunities offered by mobile technologies.” One notices that this definition does not exactly match with the Idea of MCM, because the location where you have to solve the task is predetermined. Therefore, it is a process of "mobile learning at predetermined locations".

In the MCM-project mathematics should be discovered and experienced using math problems, which are based on real examples of daily life situations and have to be done on the spot. For many students this is an entirely new perspective on their environment. The discrepancy between the previous and the new perception produces curiosity, which can be defined as a prime example for intrinsic motivation (McLean, 2003). Intrinsic motivation also arises because of the fact that mathematic education takes place in an out-of-school activity. Furthermore new, and for students interesting, technologies are used which is a discrepancy to their previous perception, too.

The concept of stepped hints is another important component of the MCM-Project. According to Friedrich \& Mandl (1992) learning hints generally fulfil the following functions: to paraphrase, to focus, to elaborate sub-goals, to activate prior knowledge, to visualize. However, it is not excluded that single learning hints can have several functions. The main goal of hints is to give students the opportunity to treat and solve math problems independently. Even if they fail at their first solution process, they can get a result with the help of the learning aids. Studies (Franke-Braun, Schmidt-Weigand, Stäudel, \& Wodzinski, 2008) are shown that stepped hints have a positive impact on learning performance, learning experience and communication.

\subsection{Modelling}

Referring to the modelling cycle according to Blum and Leiss (2005) (Fig.1) we can see that there are several step to go before a problem solver succeed. In total there are seven steps. "Mathematical modelling competency" has been defined as "the ability to identify relevant questions, variables, relations or assumptions in a given real world situation, to translate these into mathematics and to interpret and validate the solution of the resulting mathematical problem in relation to the given situation, as well as the ability to analyze or compare given models by investigating the assumptions being made, checking properties and scope of a given model etc.” (see Blum et al. 2007, p. 12). We know through the research of BoromeoFerri (2006) that some of the students do not pass the circle consecutively, but they sometimes jump directly from the real situation to the mathematical model or go forth and back several times between the real world and mathematics world. 


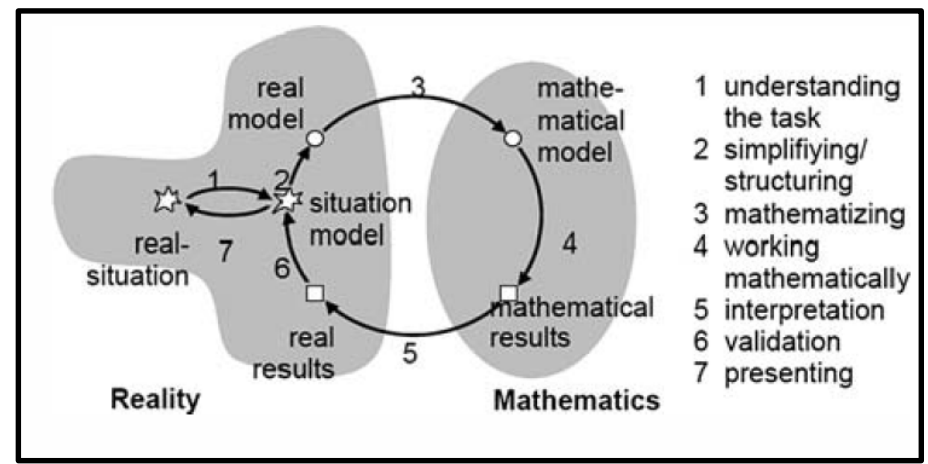

Figure 1. Modelling cycle according to Blum and Leiß(2015).

\subsection{Difficulties integrating new technologies into math classes}

With new technology in schools, the question has always been, do teachers work with the new tools, how do they use them and so on. Paul Drijvers made a study in 2012 about the factors for successful use of new technology amongst teachers. One of the three important factors is the role of the teacher (Drijvers, Boon \& Van Reeuwijk, 2010). A majority of the German teachers report to have not enough time beside their daily tasks at school (Schneider, 2015 p. 20). The time a new tool needs to be set up is an important issue. We will show that MCM simplifies the creation process of designing tasks and trails and make it less time consuming.

\section{The MCM Project}

Through the combination of the math trail idea (embodiment, outdoor, being active), mobile devices and mathematical modelling, one can describe the idea behind the MCM project. 


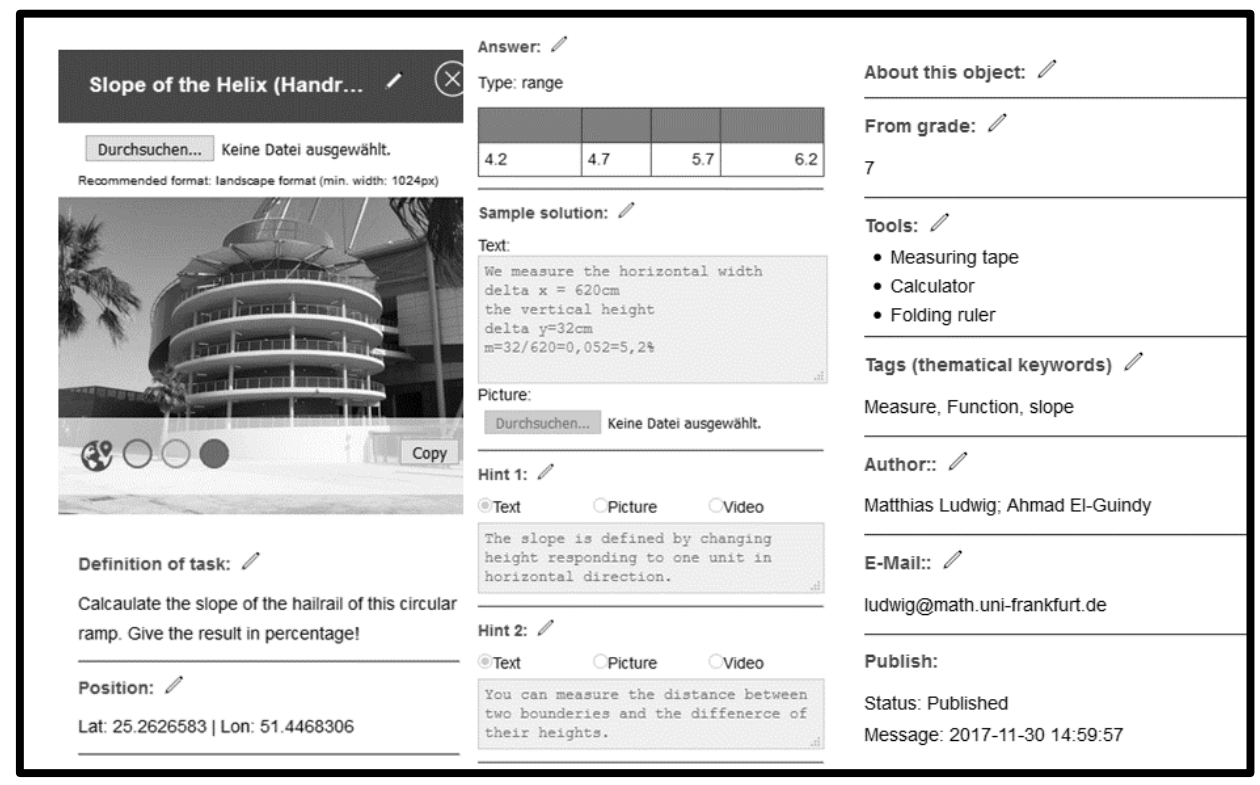

Figure 2: The filled in data form of a MCM task.

The intention of MCM is to automate many steps in the creation of the math trail guide and to provide a collection of tasks and trails that can be freely used or just viewed to get inspiration for own tasks. Furthermore, it gives users (e.g. groups of students) the possibility to go on a math trail more independently by using mobile devices' GPS functions to find the tasks location. Further, it gives feedback on the users' answers and provides hints on demand. The core of the MCM project can be divided into two parts: the MCM web portal and the MCM app.

\subsection{MCM web portal - www.mathcitymap.eu}

At first sight, the web portal is a data base. After a short registration, the user can view the content of the data base which consists of public trails and tasks. It is also possible to create own tasks by providing the necessary data (position, the task itself, the sample solution, the answer as interval, exact value or multiple choice, an image of the object, stepped hints) (see Figure 2). To create a math trail one combines different tasks by clicking. For every math trail, the math trail booklet can be downloaded as PDF or accessed via the MCM-App. It contains all tasks information, a map of the trail and a title page (see Figure 3). 


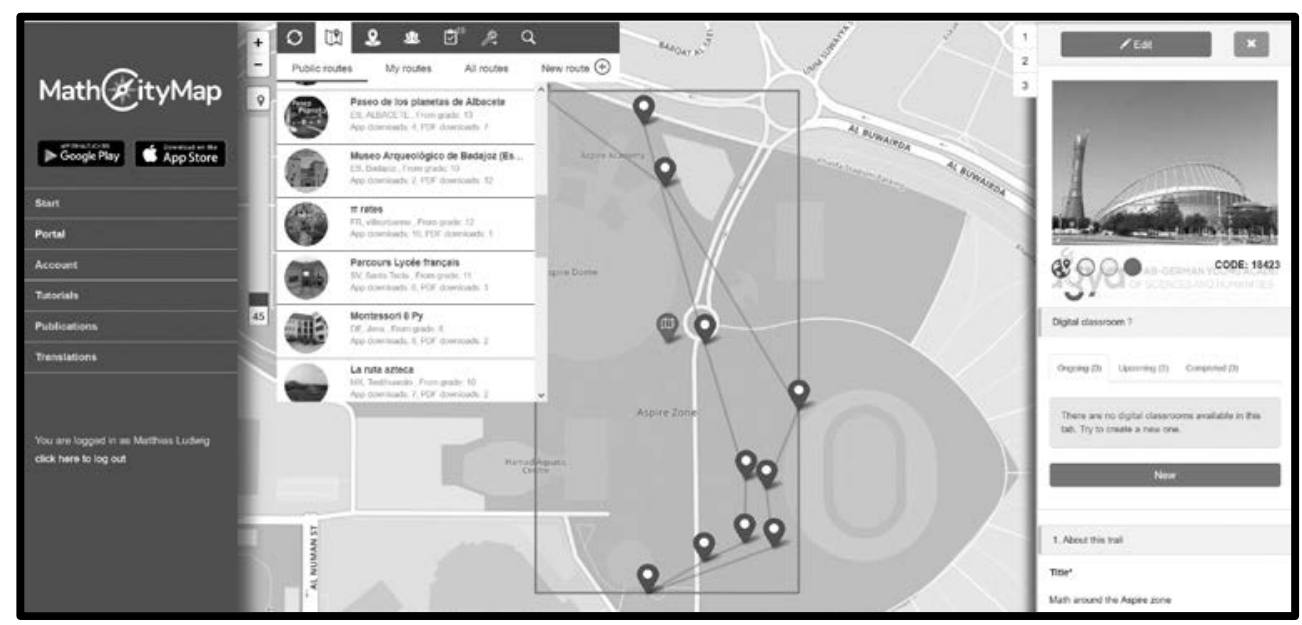

Figure 3: A math trail (polygon) with the all the tasks symbolized by blue pins.

\subsection{MCM app for mobile devices}

The MCM app allows the user to access math trails created with the web portal. The trail data, such as images and map tiles, can be downloaded to the mobile device. After this procedure, it is possible to use a trail without internet connection. Furthermore, the app offers an open street map overview for orientation purposes, the task itself, a stepped hint system and a feedback on the entered answers. (see Figure 4)

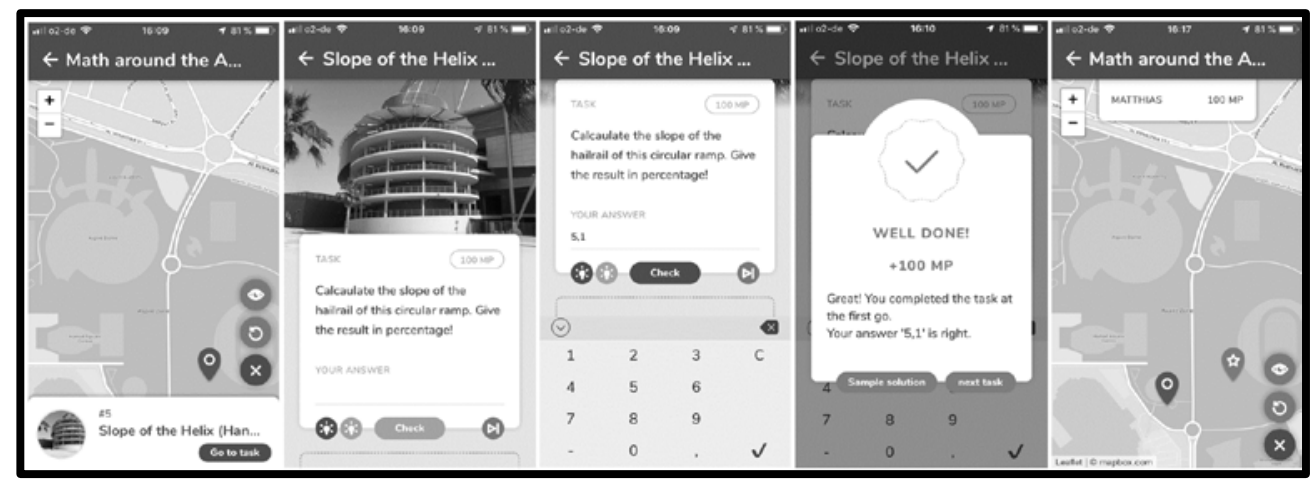

Figure 4: The map with the first task, the task itselfs, the keyboard to type in the solution, the feedback, the green pin shows the solved task and the blue pin show the next task toi solve.

The hint system has the purpose to enable pupils to solve the tasks independently and additionally has a positive impact on learning performance, learning experience and communication (Franke-Braun, Schmidt-Weigand, Stäudel, \& Wodzinski, 2008). 


\section{Modelling and the MCM project}

The processing of a MCM task basically requires the complete running through of the modeling cycle, (see Figure 1). Nevertheless, in many MCM tasks, one can recognize a focus on simplifying and mathematicising the real situation, which corresponds to steps 2 and 3 here. Simplifying separates important from unimportant information taken from the real situation. Mathematization (step 3) is followed by the translation of the simplified real situation into mathematical models (step 2) (see Greefrath, Kaiser, Blum \& Borromeo Ferri, 2013).

The following task was part of a math trail. The trail was running by $1539^{\text {th }}$ graders and 52 undergraduates' university teacher students. We divide the students normal into group of three, so we get 51 groups of $9^{\text {th }}$ grades and 17 groups of undergraduates. It was a mixed trail with different tasks about combinatorics, numbers, solid geometry and probability. The task we want to emphasize in this paper was: "Calculate the volume of the flowerpot. Give the result in liters!”. In figure 5 on the left you see the task how it appears on the prepared smartphone (1).

After the students run the trail, we collect the phones and the students' notes. The shape of the flowerpot is obviously a truncated cone, but when you not know the formula of the volume of the truncated cone, you have to deal with the situation in other ways. We categorize the students' solutions and found four categories for this task. First category is "task is not solved” this means nothing is written down, or a very fancy solution which you cannot connect to the task itself. The other three categories we show in figure 5 (picture 2-4). Each solution deals with different mathematical models. In each category, the students have to create their own real model and then they mathematize by adding variables they have to measure. They have to think about which data they have to measure. This is really the difference to modelling tasks in the Classroom. The solution (2) in figure 5 use the mean of the small and big diameters of the truncated cone and calculates the volume with a formula of a cylinder $\left(V=\left(\frac{R+r}{2}\right)^{2} \cdot h \cdot \pi\right)$. The solution on the right (3) of figure 5 deal with the volumes of two cylinders corresponding to the small and big diameters of the truncated cone. The result is the mean of both volumes of the cylinders $\left(V=\frac{R^{2}+r^{2}}{2} \cdot h \cdot \pi\right)$. The solution (4) on the bottom of figure 5 appeared when the student knows the formula of the volume of a truncated cone $\left(V=\frac{R^{2}+R r+r^{2}}{3} \cdot h \cdot \pi\right)$ and uses it. It is very interesting that at the end the results of the students do not differ very much. On one side this is because of the exact measurements and on the other side because the shape of the truncated cone does not differ very much from a cylinder. To give the students feedback on the appropriateness of their models, the MCM App uses solutions intervals. The intervals based on calculation of errors and experiences of the task creator. 


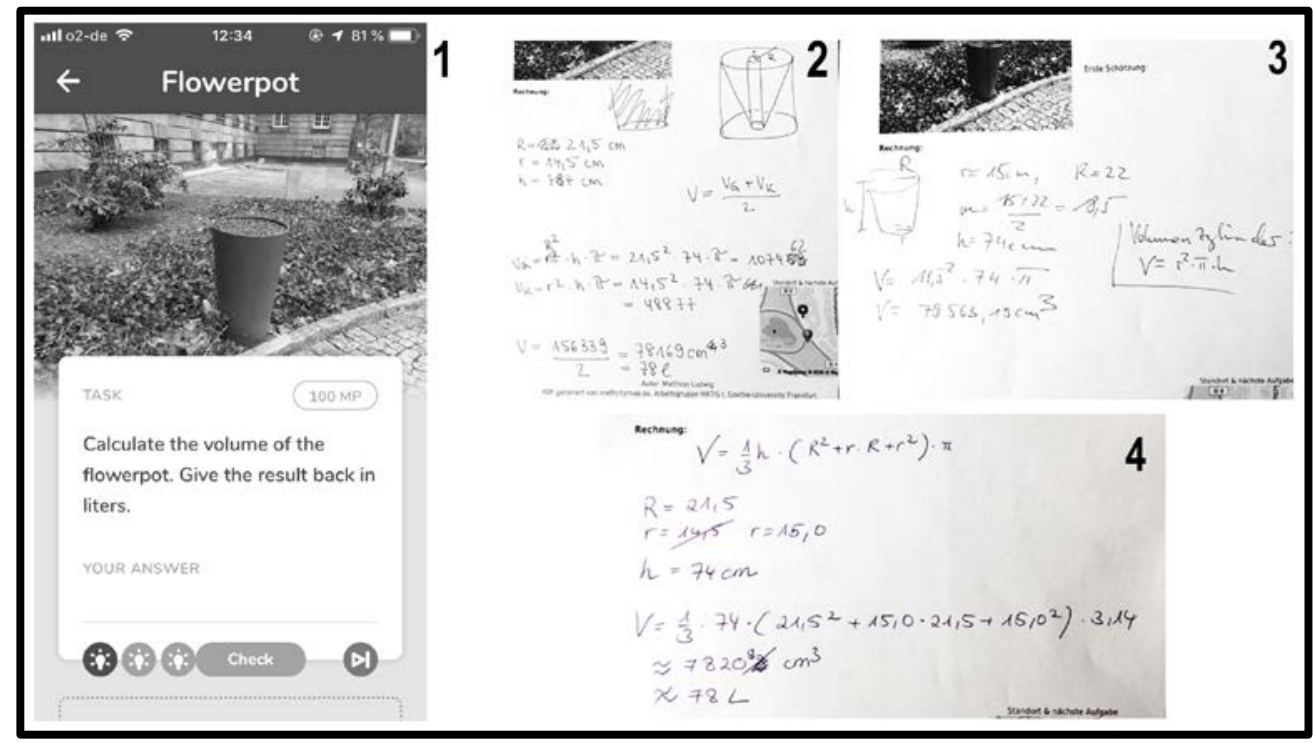

Figure 5: The flowerpot task how it appears in the App (1) and the three student solutions for the flowerpot task

When we look on the numbers of student groups who uses which solution approach we found that $20 \%$ of the $9^{\text {th }}$ grades are not able to solve the task in an appropriate way. But approach 2 (mean of the radii, see fig. 5 (3) ) is used very often (60\%). Some of them use the second approach in another way. They measure the circumference of the truncated cone in the middle of his height and get the mean circumference in once. The third approach (create the mean of a big and small cylinder) is used very seldom.

\section{Results and Discussion}

The MCM-Community (2000+ users) creates in the last two years more than 900 math trails and more than 5500 tasks with the MCM system. An ordinary trail has about 9 to twelve task. Each task get a number. The students work together in groups of three. Each groups starts on a certain task. When the group finished the task they move clockwise to the task with the next number. In an normal educational context every group uses theirs own prepared smartphone with the MCM-App, which contains all the trail and task information (GPS Coordinates, hints, sample solution) and a paper trail guide which they can use for sketches and written calculation.

In total, we see that doing math on real objects lead the students in a natural way to structure and simplify a task. Then they create a real model, mathematize it by adding variables and do measurements. At the end the students get a feedback from the app and they validate their 
solution. Overall we can say the MCM-System helps to teach the beginning of mathematical modelling

\section{References}

Blum, W., Galbraith, P. L., Henn, H.-W., \& Niss, M. (2007). Modelling and applications in mathematics education: the 14th ICMI study. New York: Springer.

Blum,W., \& Leiss, D. (2005). How do students and teachers deal with mathematical modelling problems? The example "Sugarloaf”. In ICTMA 12 proceedings, pp. 222-231.

Boromeo-Ferri, R. (2006). Theoretical and empirical differentiations of phases in the modelling process. ZDM, 38(2), 86-95.

Blane, D.C. \& Clark, D. (1984). A Mathematics Trail Around the City of Melbourne. Monash Mathematics Education Centre, Monash University.

Drijvers, P., Boon, P., \& Van Reeuwijk, M. (2010). Algebra and technology. In P. Drijvers (Ed.), Secondary algebra education. Revisiting topics and themes and exploring the unknown (pp. 179-202). Rotterdam, The Netherlands: Sense.

Franke-Braun, G., Schmidt-Weigand, F., Stäudel, L., \& Wodzinski, R. (2008). Aufgaben mit gestuften Lernhilfen - ein besonderes Aufgabenformat zur kognitiven Aktivierung der Schülerinnen und Schüler und zur Intensivierung der sachbezogenen Kommunikation. In R. Messer \& W. Blum (Eds.), Lernumgebungen auf dem Prüfstand. Zwischenergebnisse aus den Forschungsprojekten (pp. 27-42). Kassel: Kassel Univ. Press.

Friedrich, H. F., \& Mandl, H. (1992). Lern- und Denkstrategien - ein Problemaufriß. . In: H. F. Friedrich, H. Mandl (Hrsg.): Lern- und Denkstrategien , S. 3-54.

Greefrath, G.; Kaiser, G.; Blum, W. \& Borromeo Ferri, R. (2013). Mathematisches Modellieren - Eine Einführung in theoretische und didaktische Hintergründe. In: Mathematisches Modellieren für Schule und Hochschule. Wiesbaden: Springer Spektrum, S. 11-38.

McLean, A. (2003). Third gear - intrinsic motivation. In A. McLean, The motivated school (pp. 83-85). London: Paul Chapman.

O'Malley, C., Vavoula, G., Glew, J., Taylor, J., Sharples, M., \& Lefrere, P. (2003). Guidelines for learning/teaching/tutoring in a mobile environment. MOBIlearn deliverable D, Vol. 4

Schneider, W. (2015). Zeit für Bildung - Eine Befragung unter Lehrerinnen und Lehrern. PM, 53, 14-19.

Shoaf, M., Pollak, H. \& Schneider, J. (2004). Math Trails. Lexington: COMAP.

Vos, P. (2011). What is 'authentic' in the teaching and learning of mathematical modelling?. In G. Kaiser, W. Blum, R. Borromeo Ferri, \& G. Stillman (Eds.), Trends in teaching and learning of mathematical modelling: ICTMA 14 (pp. 713-722). New York: Springer. 